\title{
Article \\ Histone Deacetylase 3 Regulates Adipocyte Phenotype at Early Stages of Differentiation
}

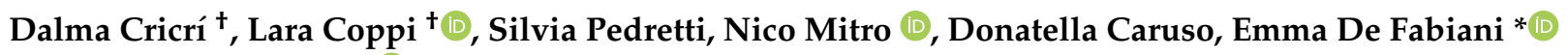 \\ and Maurizio Crestani *(D)
}

check for

updates

Citation: Cricrí, D.; Coppi, L.; Pedretti, S.; Mitro, N.; Caruso, D.; De Fabiani, E.; Crestani, M. Histone Deacetylase 3 Regulates Adipocyte Phenotype at Early Stages of Differentiation. Int. J. Mol. Sci. 2021, 22, 9300. https://doi.org/10.3390/ ijms22179300

Academic Editor: Maria

Luisa Balestrieri

Received: 2 August 2021

Accepted: 23 August 2021

Published: 27 August 2021

Publisher's Note: MDPI stays neutral with regard to jurisdictional claims in published maps and institutional affiliations.

Copyright: (c) 2021 by the authors. Licensee MDPI, Basel, Switzerland. This article is an open access article distributed under the terms and conditions of the Creative Commons Attribution (CC BY) license (https:// creativecommons.org/licenses/by/ $4.0 /)$.
Dipartimento di Scienze Farmacologiche e Biomolecolari, Università degli Studi di Milano, Via Balzaretti 9, 20133 Milano, Italy; dalma.cricri@unimi.it (D.C.); lara.coppi@unimi.it (L.C.); silvia.pedretti@unimi.it (S.P.); nico.mitro@unimi.it (N.M.); donatella.caruso@unimi.it (D.C.)

* Correspondence: emma.defabiani@unimi.it (E.D.F.); maurizio.crestani@unimi.it (M.C.); Tel.: +39-025-031-8329 (E.D.F.); +39-025-031-8393 (M.C.)

+ These authors contributed equally to this work, and they should be considered both first author.

\begin{abstract}
Obesity is a condition characterized by uncontrolled expansion of adipose tissue mass resulting in pathological weight gain. Histone deacetylases (HDACs) have emerged as crucial players in epigenetic regulation of adipocyte metabolism. Previously, we demonstrated that selective inhibition of class I HDACs improves white adipocyte functionality and promotes the browning phenotype of murine mesenchymal stem cells (MSCs) C3H/10T1/2 differentiated to adipocytes. These effects were also observed in $d b / d b$ and diet induced obesity mouse models and in mice with adipose-selective inactivation of HDAC3, a member of class I HDACs. The molecular basis of class I HDACs action in adipose tissue is not deeply characterized and it is not known whether the effects of their inhibition are exerted on adipocyte precursors or mature adipocytes. Therefore, the aim of the present work was to explore the molecular mechanism of class I HDAC action in adipocytes by evaluating the effects of HDAC3-specific silencing at different stages of differentiation. HDAC3 was silenced in $\mathrm{C} 3 \mathrm{H} / 10 \mathrm{~T} 1 / 2 \mathrm{MSC}$ at different stages of differentiation to adipocytes. shRNA targeting HDAC3 was used to generate the knock-down model. Proper HDAC3 silencing was assessed by measuring both mRNA and protein levels of mouse HDAC3 via qPCR and western blot, respectively. Mitochondrial DNA content and gene expression were quantified via qPCR. HDAC3 silencing at the beginning of differentiation enhanced adipocyte functionality by amplifying the expression of genes regulating differentiation, oxidative metabolism, browning and mitochondrial activity, starting from $72 \mathrm{~h}$ after induction of differentiation and silencing. Insulin signaling was enhanced as demonstrated by increased AKT phosphorylation following HDAC3 silencing. Mitochondrial content/density did not change, while the increased expression of the transcriptional co-activator Ppargc1b suggests the observed phenotype was related to enhanced mitochondrial activity, which was confirmed by increased maximal respiration and proton leak linked to reduced coupling efficiency. Moreover, the expression of pro-inflammatory markers increased with HDAC3 early silencing. To the contrary, no differences in terms of gene expression were found when HDAC3 silencing occurred in terminally differentiated adipocyte. Our data demonstrated that early epigenetic events mediated by class I HDAC inhibition/silencing are crucial to commit adipocyte precursors towards the above-mentioned metabolic phenotype. Moreover, our data suggest that these effects are exerted on adipocyte precursors.
\end{abstract}

Keywords: epigenetics; obesity; HDAC3; adipocytes; differentiation; metabolism; inflammation

\section{Introduction}

Overweight and obesity are defined by the World Health Organization as abnormal or excessive fat accumulation that presents a risk to health. Patients are classified as overweight when the body mass index (BMI) is above $25 \mathrm{~kg} / \mathrm{m}^{2}$ or obese if above 
$30 \mathrm{~kg} / \mathrm{m}^{2}$ [1]. The prevalence of these conditions is climbing worldwide; in 2016, 39\% of adults were overweight and $13 \%$ were obese [2]. They represent primary risk factors for a broad range of severe pathologies such as cardiovascular disease [3], type 2 diabetes [4], musculoskeletal disorders [5] and cancer [6]. Despite the increasing prevalence, available strategies for prevention and treatment of obesity have shown mild effectiveness to date [7]. Thus, further investigations on pathogenesis mechanisms and potential therapeutic approaches are required for lowering the risks of an overweight and obesity pandemic and the related comorbidities.

In addition, overweight and obesity are associated with low-grade chronic inflammation mainly related to immune dysregulation within adipose tissue [8]. M1 proinflammatory macrophages are the most abundant immune cells accumulating and releasing pro-inflammatory cytokines that contribute to the development of obesity complications [9]. On the other hand, pro-inflammatory stimuli have also been shown to be essential for adipogenesis and adipose tissue physiology. Adipocyte metabolism and functionality are affected in a mouse model with adipose tissue-specific reduction of inflammation. As a consequence of reduced adipogenesis, fat storage capacity decreases and results in ectopic fat accumulation, hepatic steatosis and glucose intolerance [10].

Adipose tissue mass is consequent to cell proliferation and differentiation of precursors to mature adipocytes. This represents a physiological process essential to adipose tissue development and turnover [11]. Moreover, a pool of multipotent stromal vascular cells populates adipose tissue guaranteeing tissue renewal [12], while the regulation of this process is altered in overweight or obese subjects [13].

Differentiation of precursor cells to adipocytes is highly regulated by a transcriptional cascade that directs gene expression programming [14]. This process is defined as adipogenesis and it is activated by a complex cascade of transcriptional factors. The first wave of activation is initiated by CREB (cAMP response element binding protein) and members of the C/EBP (CCAAT/enhancer-binding protein) family such as C/EBP $\beta$. Moreover, other early adipogenic factors such as SREBP-1c (sterol regulatory element binding protein-1c) play a relevant role during this stage [15]. Their action determines a second wave of transcriptional activation, mainly mediated by the nuclear receptor peroxisome proliferator-activated receptor $\gamma(\operatorname{PPAR} \gamma)$. Furthermore, $\mathrm{C} / \mathrm{EBP} \alpha$ is an important late adipogenic factor stimulating and amplifying PPAR $\gamma$ action [16].

Adipose tissue is classified in white adipose tissue (WAT) and brown adipose tissue (BAT) [17]. BAT originates during embryonal development and it is mainly involved in heat production due to uncoupling protein 1 (UCP1) action, which uncouples the respiratory chain within the inner mitochondria membrane from ATP production [18]. In contrast, WAT is primarily important for energy storage under the form of triacylglycerols [19]. Furthermore, WAT covers relevant endocrine functions such as glucose homeostasis regulation through adipokines release [20]. BAT and WAT also have significant morphologic differences. In fact, brown adipocytes are characterized by a high number of mitochondria with intense oxidative activity and interspersed among multilocular lipid droplets; white adipocytes typically present unilocular droplets where triglycerides are stored [21]. Beside white and brown adipocytes, beige adipocytes present intermediate characteristics. The process related to cell differentiation to brown-like phenotype is defined as "browning" [22]

Epigenetic modifications modulate gene expression by acting on chromatin remodeling [23]. Epigenome modifiers have been shown to play a crucial role in adipose tissue metabolism, predisposition and development of obesity [24-26]. Histone deacetylases (HDACs) catalyze the removal of acetyl groups from histones promoting chromatin condensation and reducing gene expression. To date, four different classes of HDACs have been described. Class I histone deacetylases includes HDAC 1, 2, 3 and 8, all localized in the nucleus and with pronounced activity on histones; their expression is ubiquitarian. Class II HDACs (HDAC 4, 5, 6, 7, 9, 10) shuttle between nucleus and cytoplasm and do not have marked activity on histones. Class III is represented by sirtuins, and class IV includes only HDAC11, which does not have a clear role [27]. 
By using both genetic and diet-induced obese mouse models, we previously showed that the selective inhibition of class I HDACs with the small molecule MS-275 improved obese phenotype and insulin sensitivity in vivo [28,29]. Moreover, in vitro MS-275 stimulates adipocyte metabolism promoting expression of genes related to adipocyte differentiation and functionality, including Pparg, a master regulator of the adipocyte phenotype [30], browning (Ucp1) and oxidative metabolism that supports thermogenesis. Knockout in adipose tissues in mice and shRNA-mediated silencing in adipocyte cultures of HDAC3 recapitulated browning and the metabolic rewiring observed with the HDAC inhibitor MS-275 [31]. However, it should be noted that the effects of HDAC inhibitors may not necessarily overlap those deriving from genetic ablation or silencing of a specific HDAC. HDAC inhibitors reduce the catalytic activity of these proteins, while they may not affect other possible features of the same proteins that are not linked to their catalytic activity. Thus, genetic ablation or silencing of a specific HDAC could lead to results that do not completely overlap with those obtained with a chemical inhibitor. As an example, HDAC3 has been shown to act as a coactivator, independently from its catalytic activity, in macrophages, where it activates the expression of inflammatory genes via a non-canonical mechanism [32]. Therefore, it is crucial to assess the role of HDAC3 in the adipocyte phenotype by testing the effects of its silencing, as opposed to chemical inhibition. Moreover, to further explore whether a specific class I HDAC regulates adipose tissue functions at different stages of differentiation, we asked whether depletion of HDAC3 affects adipocyte precursors or mature adipocytes. Our results indicate that the main effects were achieved only when HDAC3 expression was reduced at an early stage of adipocyte differentiation, while depletion of HDAC 3 in mature adipocytes did not lead to major changes of their phenotype.

\section{Results}

\subsection{Early Silencing of HDAC3 Amplifies Adipocyte Differentiation and Functionality}

To gain insights into the molecular basis of class I HDACs in adipose tissue and establish whether the phenotypic effects observed using the class I HDAC inhibitor MS-275 were related to precursors or mature adipocytes, MSCs were induced to differentiate to adipocytes and HDAC3 was silenced at the beginning (day 0) and at the end (day 7) of the differentiation, as shown in the scheme in Figure 1. Silencing was confirmed both at mRNA and protein level (Figure 2).

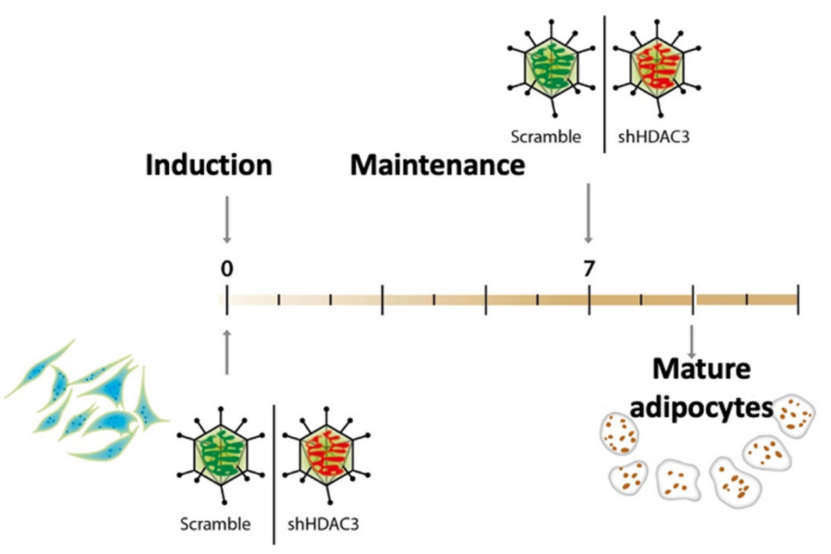

Figure 1. $\mathrm{C} 3 \mathrm{H} / 10 \mathrm{~T} 1 / 2$ cells induced to differentiate to adipocytes using a standard hormonal cocktail and maintained until terminally differentiated. HDAC3 was silenced by adenovirusmediated short hairpin RNA interference at the beginning of differentiation (day 0 ) or at the end of differentiation (day 7). 


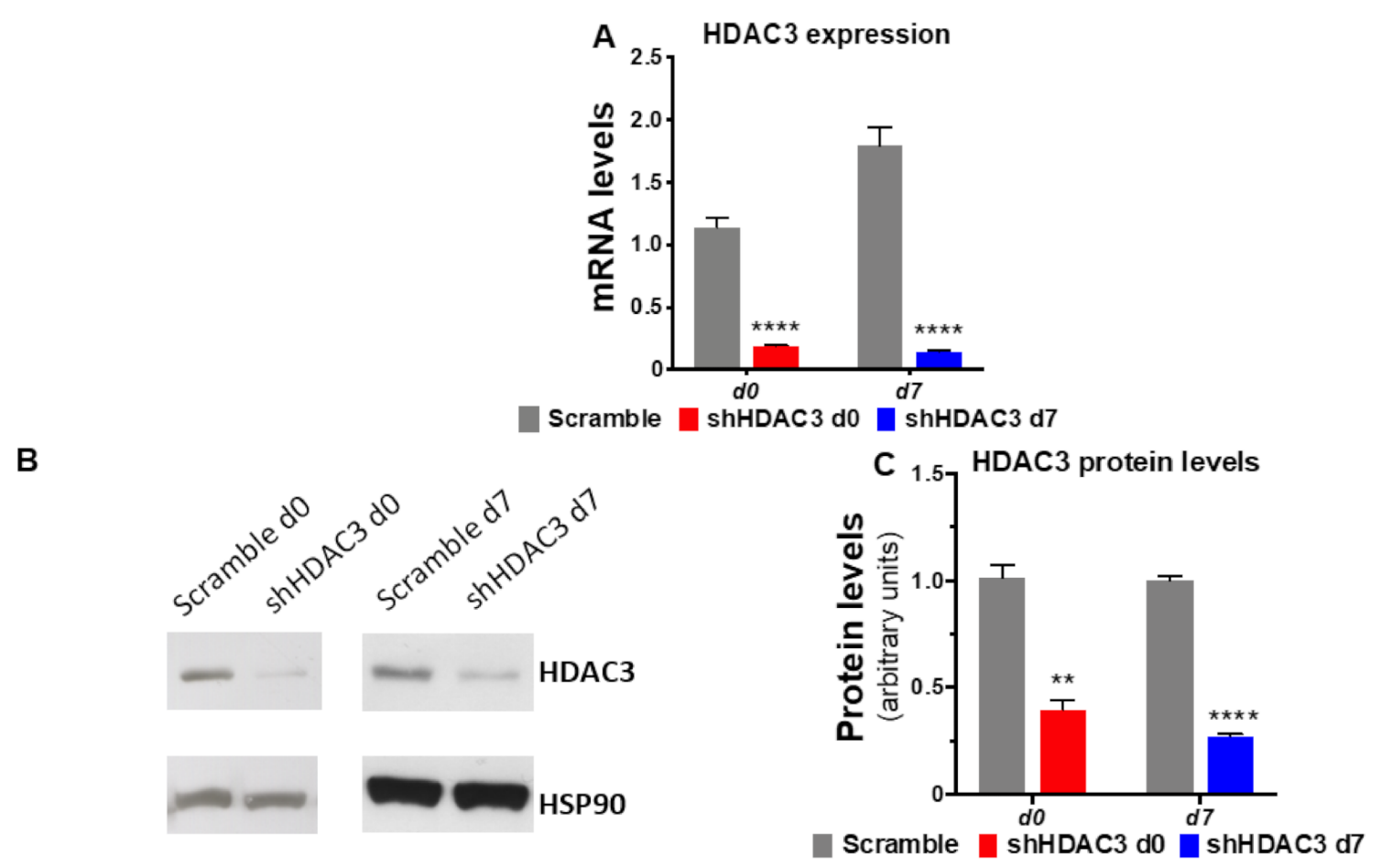

Figure 2. Silencing of HDAC3 confirmed at mRNA and at protein level. (A) mRNA expression data are presented as mean \pm SEM ( $n=9$ from 3 independent experiments). (B) Representative western blot of HDAC3 protein levels from three independent experiments. (C) Quantitation of HDAC3 protein levels in C3H/10T1/2 adipocytes silenced at day 0 or at day 7 of differentiation ( $n \geq 3$ from 3 independent experiments). Cells silenced at day 0 were harvested at day 9 after induction of differentiation, while cells silenced at day 7 were harvested at day 11 after induction of differentiation. Statistical analyses were performed using unpaired Student's $t$-test, ${ }^{* *} p<0.01$ and ${ }^{* * * *} p<0.0001$, respectively.

HDAC3 silencing at day 0 significantly increased the expression of genes important for adipocyte differentiation and functionality. In particular, the mRNA levels of Pparg, Cebpa and carbohydrate-responsive element-binding protein $\beta$ (Chrebpb), key transcriptional regulators of adipogenesis, increased following HDAC3 silencing at $\mathrm{d} 0$ of differentiation (Figure 3A), while no change at the mRNA levels of these transcription factors was noted when HDAC3 was silenced at $\mathrm{d} 7$ of differentiation (Figure 3B). Accordingly, the protein level of PPAR $\gamma 2$, the receptor isoform specific to adipocytes, was higher, whereas the PPAR $\gamma 1$ protein level did not change (Figure 3C,D). Since Chrebpb expression has been shown to predict insulin sensitivity through upregulation of de novo lipogenesis in adipose tissue [33], we were prompted to test the insulin receptor cascade activation in C3H/10T1/2 adipocytes in which we silenced HDAC3. As shown in Figure 3E,F, western blot analysis indicates that early silencing of HDAC3 increases AKT phosphorylation, a known marker of insulin receptor activation.

We also detected increased expression of several markers of adipocyte functionality with HDAC3 early silencing. For instance, the expression of lipid droplet-associated protein perilipin (Plin), fatty acid-binding protein 4 (Fabp4), adiponectin (Adipoq) and glucose transporter 4 (Glut4) increased (Figure $3 \mathrm{~A}$ ), suggesting amplified adipogenic potential (Figure 3A). In contrast, when HDAC3 was silenced in mature adipocytes, the expression profile of the same genes was not affected (Figure 3B). The results of the expression of genes relevant for adipocyte differentiation were consistent with a greater number of differentiated adipocytes when HDAC 3 was silenced at day 0 vs. cells treated with scramble RNA (Figure 4A), while no difference was detected in the number of differentiated adipocytes when HDAC3 was silenced at day 7 vs. cells treated with scramble RNA (Figure 4B). Oil Red O (ORO) staining confirmed that HDAC3 silencing at $\mathrm{d} 0$ of differentiation increased lipid content in adipocytes, whereas the increase of lipid content was significantly lower 
with HDAC3 silencing at $\mathrm{d} 7$ (2.5-fold with HDAC3 silencing at $\mathrm{d} 0$ vs. 1.5 -fold change with HDAC3 silencing at $\mathrm{d} 7$, Figure $4 \mathrm{C}$ and inset).

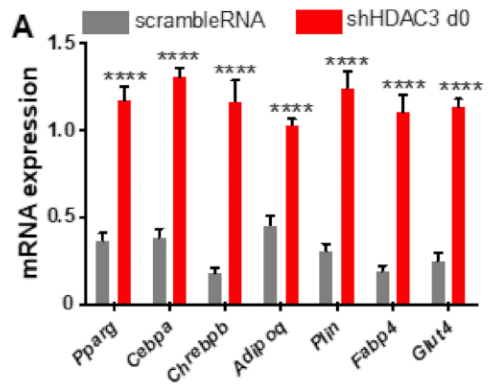

C

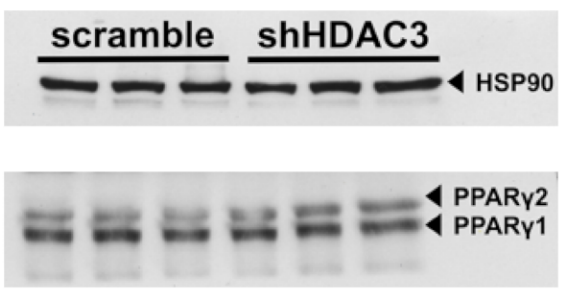

E

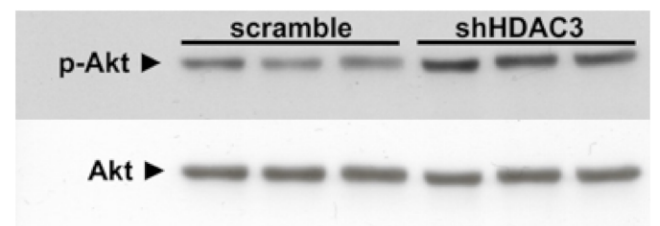

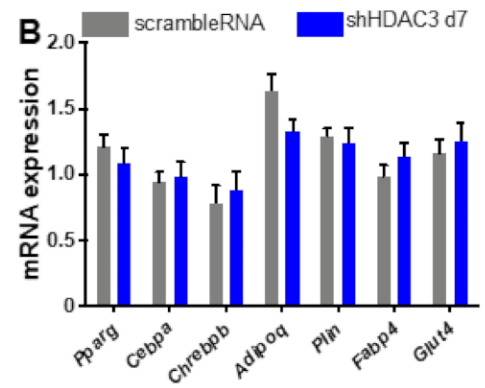

D PPAR $\gamma 2$ protein level

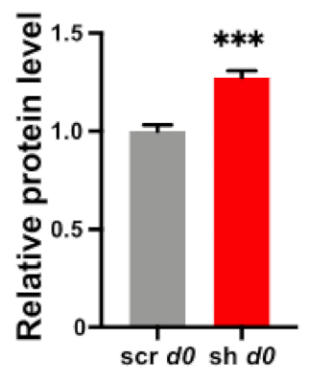

F phospho-AKT/tot-AKT

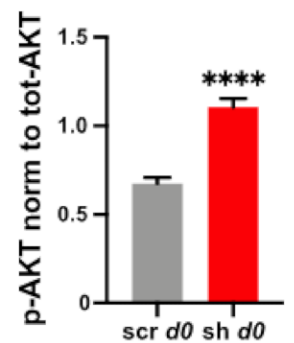

Figure 3. Expression of genes regulating adipocyte differentiation and functionality in C3H/10T1/2 cells infected with scramble/shHDAC3 at day 0 (A) or at day 7 (B) of differentiation to adipocytes. Cells silenced at day 0 were harvested at day 9 after induction of differentiation, while cells silenced at day 7 were harvested at day 11 after induction of differentiation. Data are presented as mean \pm SEM. Statistical analyses were performed with GraphPad PRISM using unpaired Student's $t$-test, ${ }^{* * * *} p<0.0001$ ( $n \geq 8$ from 3 independent experiments). (C) Representative western blot of PPAR $\gamma$ from C3H/10T1/2 cells infected with scramble/shHDAC3 at $\mathrm{d} 0$ of differentiation to adipocytes and (D) quantification of the protein bands in panel (C); data are presented as mean \pm SEM; statistical analysis was performed with GraphPad PRISM using unpaired Student's $t$-test, ${ }^{* * *} p<0.001$ ( $n=6$ from 2 independent experiments). (E) Representative western blot of C3H/10T1/2 cells infected with scramble/shHDAC3 at d0 of differentiation to adipocytes for detection of phosphorylated Akt (p-Akt) vs. total Akt (Akt); HSP90 was used as a loading control (not shown). (F) Quantification of p-Akt/tot-Akt ratio from western blot in panel (E); data are presented as mean \pm SEM; statistical analysis was performed with GraphPad PRISM using unpaired Student's $t$-test, ${ }^{* * * *} p<0.0001$ ( $n=6$ from 2 independent experiments).

\subsection{Early Silencing of HDAC3 Promotes Oxidative Metabolism of Mature Adipocytes}

To further characterize the effect of HDAC3 silencing at day 0 or day 7 of differentiation on the phenotype of $\mathrm{C} 3 \mathrm{H} / 10 \mathrm{~T} 1 / 2$ adipocytes, we extended the analysis to genes involved in oxidative metabolism. We focused on the expression of genes regulating fatty acid uptake, lipolysis and $\beta$-oxidation. HDAC3 silencing at day 0 increased the expression of the cluster of differentiation $36(\mathrm{Cd36})$, lipoprotein lipase $(\mathrm{Lpl})$ and adipose triglyceride lipase $(A t g l)$, carnitine palmitoyl-transferase $1 \mathrm{~b}(C p t 1 b)$, carnitine-acylcarnitine translocase Slc25a20 (solute carrier family 25 member 20), hydroxyacyl-coenzyme A dehydrogenase 
(Hadh), medium-chain acyl-CoA dehydrogenase (Acadm) and peroxisomal acyl-coenzyme A oxidase 1 (Acox1) (Figure 5A). These results suggest enhanced lipid mobilization and mitochondrial fatty acid $\beta$-oxidation. These are crucial metabolic pathways that support browning of adipocytes. In contrast, HDAC3 silencing at day 7 did not affect these pathways as the expression profile of these genes was not notably altered (Figure 5B). Increased lipid catabolic activity in adipocytes with HDAC 3 silencing at $\mathrm{d} 0$ was confirmed by measuring glycerol release in the culture medium, while no difference was observed with HDAC3 silencing at d7 (Figure 5C).

\section{A}

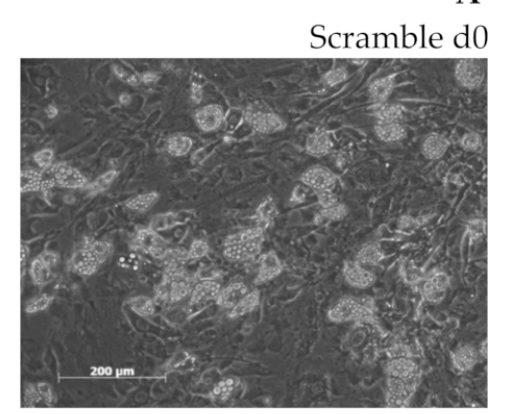

$\operatorname{shHDAC} 3 \mathrm{~d} 0$
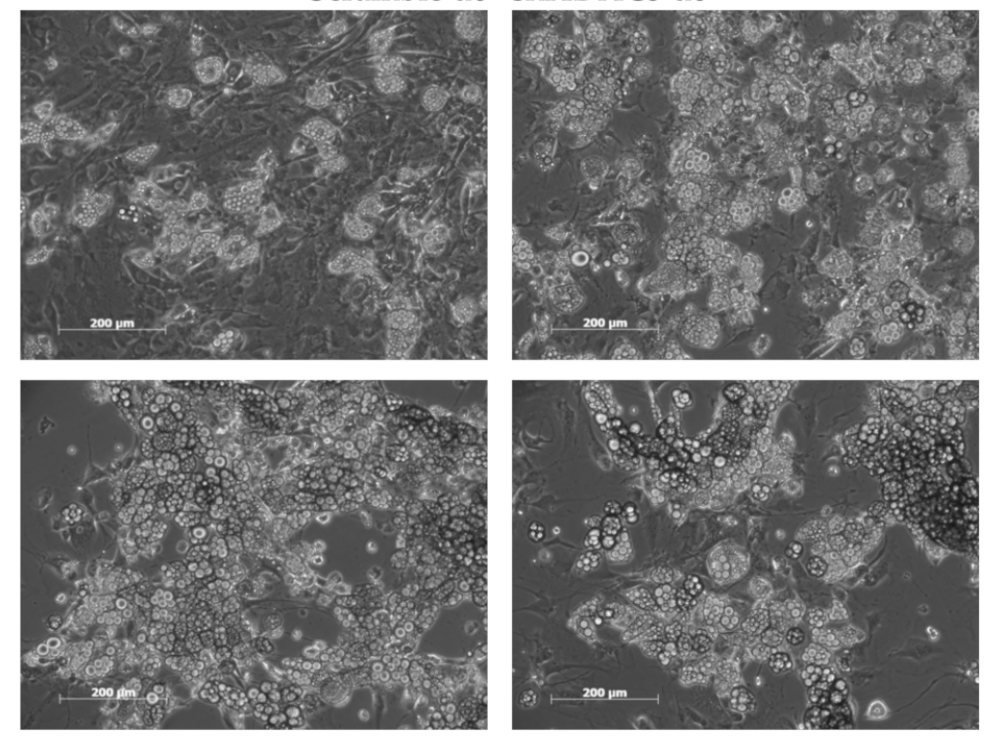

Scramble d7

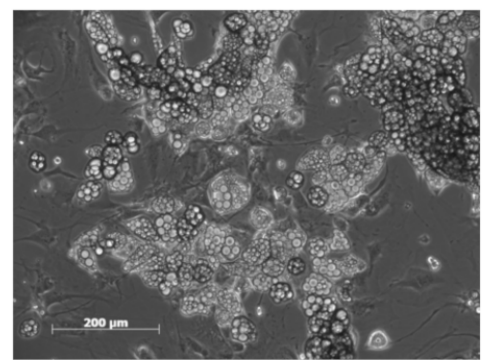

shHDAC3 d7
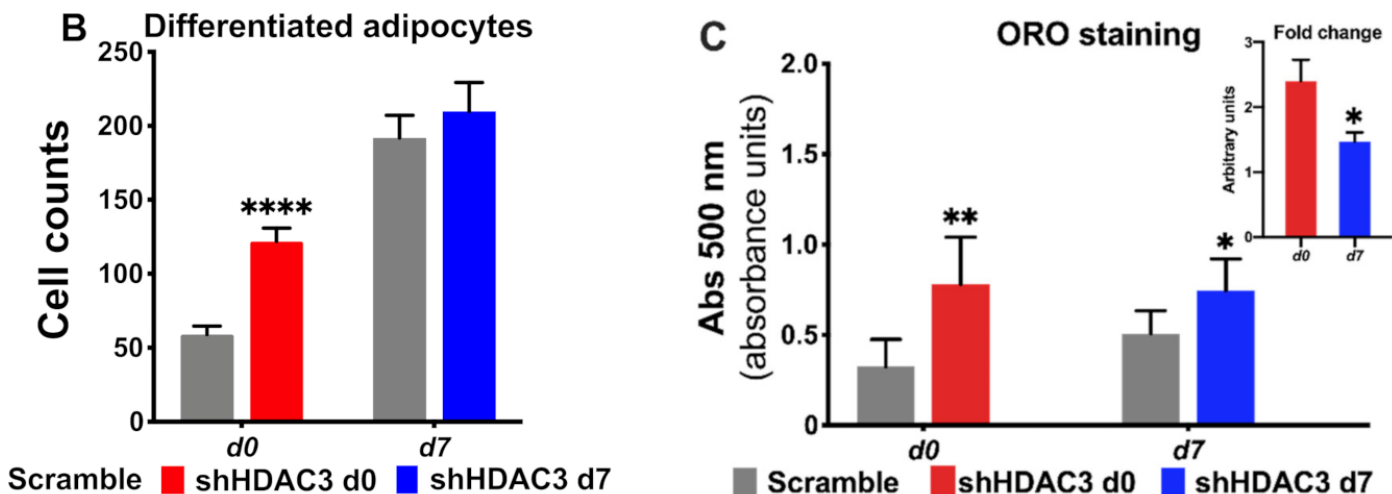

Figure 4. Early silencing of HDAC3 increases the number of differentiated adipocytes. (A) Representative images of $\mathrm{C} 3 \mathrm{H} / 10 \mathrm{T1} / 2$ MSCs with HDAC3 silencing vs. scramble controls at day 0 or day 7 of differentiation. (B) Quantification of mature adipocytes with HDAC3 silencing at day 0 or day 7 post induction of differentiation. Cells silenced at day 0 were harvested at day 9 after induction of differentiation, while cells silenced at day 7 were harvested at day 11 after induction of differentiation. Statistical analysis was performed with GraphPad PRISM using unpaired Student's $t$-test, ${ }^{* * * *} p<0.0001$ ( $n \geq 8$ counted fields/condition). (C) Oil Red O (ORO) staining to quantify lipid content in response to HDAC3 silencing. Inset shows the different fold change of lipid content induced when HDAC3 was silenced at d0 vs. d7 post induction of differentiation. Statistical analysis was performed with GraphPad PRISM using unpaired Student's $t$-test, ${ }^{*} p<0.05$ and ${ }^{* *} p<0.01(n=6)$. 

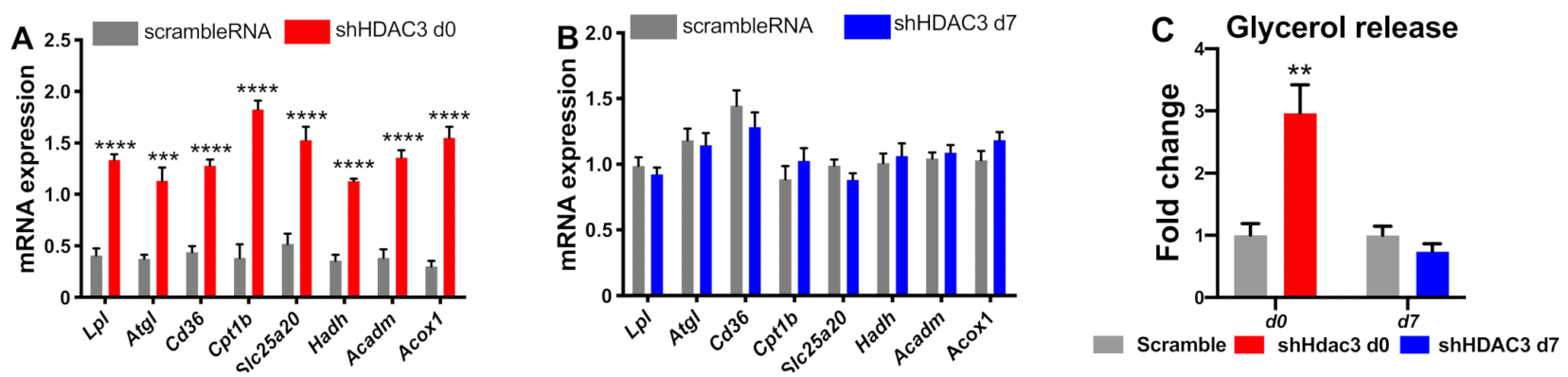

Figure 5. Expression of genes relevant for lipid mobilization and fatty acid $\beta$-oxidation in $\mathrm{C} 3 \mathrm{H} / 10 \mathrm{~T} 1 / 2$ cells infected with scramble/shHDAC3 at day $0(\mathbf{A})$ or at day $7(\mathbf{B})$ of differentiation to adipocytes. Glycerol release from adipocytes in the culture medium (C). Cells silenced at day 0 were harvested at day 9 after induction of differentiation, while cells silenced at day 7 were harvested at day 11 after induction of differentiation. Data are presented as mean \pm SEM. Statistical analysis was performed with GraphPad PRISM using unpaired Student's $t$-test, ${ }^{* *} p<0.01,{ }^{* * *} p<0.001,{ }^{* * * *} p<0.0001$ ( $n \geq 6$ from at least 2 independent experiments).

\subsection{Early Silencing of HDAC3 Stimulates Adipocyte Browning and Mithocondria Functionality}

The expression of genes involved in browning and mitochondrial functionality was also analyzed. HDAC 3 silencing at day 0 significantly increased the expression of genes involved in browning, in particular uncoupling protein 1 (Ucp1), $\beta_{3}$ adrenergic receptor (Adrb3), peroxisome proliferator activator receptor $\alpha$ (Ppara), cell death inducing DFFA-like effector $\alpha$ (Cidea), typically expressed in brown adipose tissue, and PR domain containing 16 (Prdm16), a transcriptional co-regulator of brown adipocytes differentiation (Figure 6A). However, the expression of these genes did not change when HDAC3 silencing was elicited at day 7 (Figure 6C). Moreover, HDAC3 silencing at the beginning of differentiation showed higher expression of genes important for mitochondrial functions and metabolism. In fact, the expression of isocitrate dehydrogenase subunit $\alpha$ (Idh3a), cytochrome c oxidase subunit 6a1 (Cox6a1), succinyl-CoA ligase subunit 1 (Suclg1) and peroxisome PPAR $\gamma$ coactivator $1 \beta$ (Ppargc1b) was significantly amplified (Figure 6B). On the contrary, the mRNA levels of peroxisome PPAR $\gamma$ coactivator $1 \alpha$ (Ppargc1a), master regulator of mitochondria biogenesis, significantly decreased (Figure 6B). Still, the differences of gene expression were absent when HDAC3 silencing was performed in differentiated adipocytes (Figure 6C,D), apart from Ppargc1a, whose expression was reduced, although to a lower extent than in cells with HDAC3 silencing at day 0 (Figure 6D).

Accordingly, mitochondrial DNA of cytochrome c oxidase subunit 2 (mtCox2) did not increase with HDAC3 silencing at day 0 (Figure 7A). When we measured mitochondrial functionality (Figure 7B), despite no change in basal respiration (Figure 7C), we found an increase in proton leak (Figure 7D) and maximal respiration (Figure 7E), linked to reduced coupling efficiency (Figure 7F) in HDAC3-depleted adipocytes. Furthermore, the higher expression of OXPHOS proteins (i.e., complex I, complex II and complex IV) was consistent with the increased oxidative metabolism of silenced adipocytes (Figure 7G,H).

Overall, these results indicate that silencing of HDAC3 leads to browning of mature adipocytes, with enhanced uncoupled respiration and greater capacity of oxidative metabolism. Notably, these observations also suggest HDAC3 silencing has an impact on adipocyte differentiation and metabolism regulating the early stages of adipogenesis. 

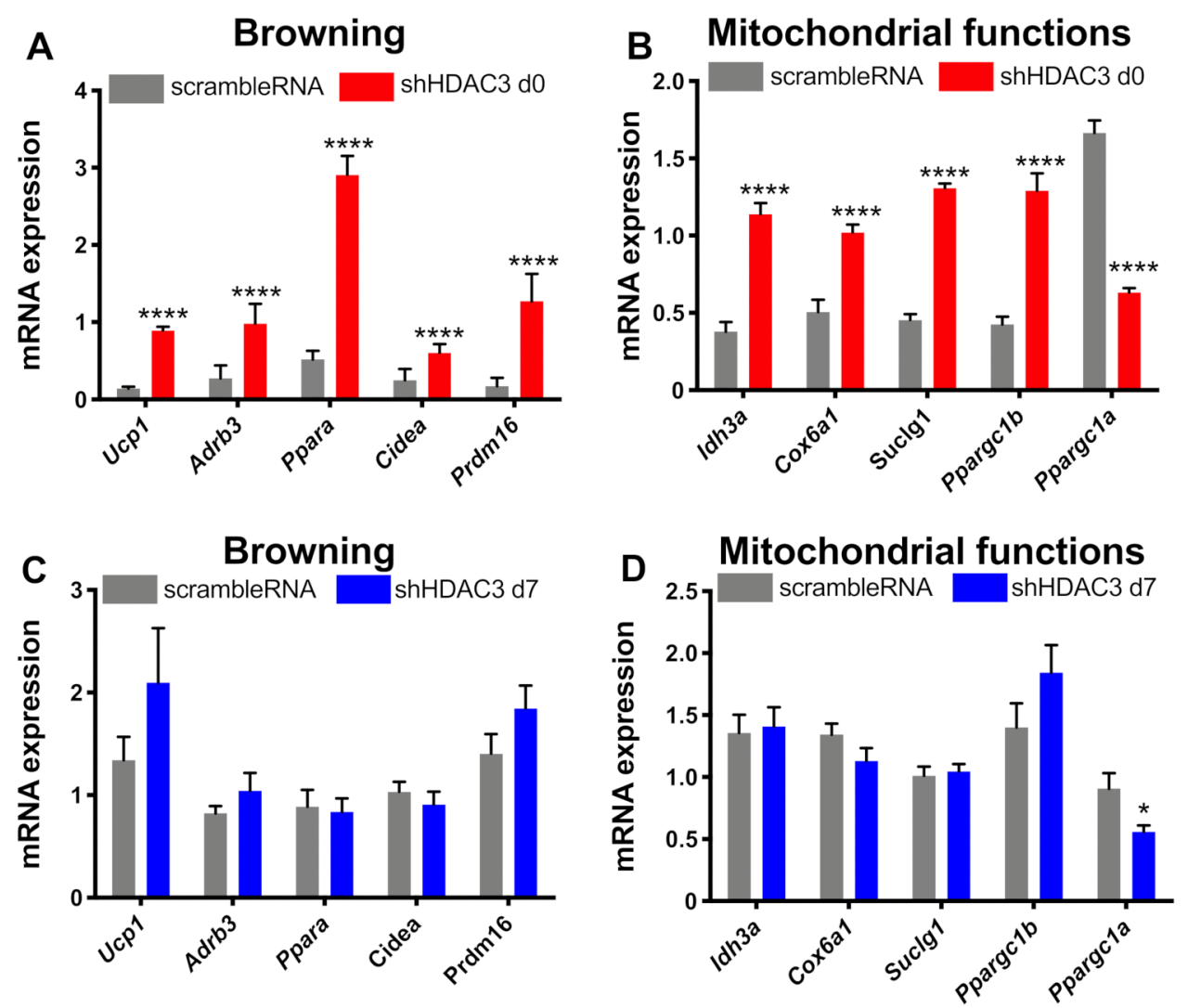

Figure 6. Expression of genes related to browning and mitochondrial functions. C3H/10T1/2 cells were infected with scramble/shHDAC3 at day 0 and expression of genes for browning (A) and mitochondrial functions (B) of differentiation to adipocytes. The expression of the same genes was measured in $\mathrm{C} 3 \mathrm{H} / 10 \mathrm{~T} 1 / 2$ cells infected with scramble/shHDAC at day 7 (C,D). Cells silenced at day 0 were harvested at day 9 after induction of differentiation, while cells silenced at day 7 were harvested at day 11 after induction of differentiation. Data are presented as mean \pm SEM. Statistical analyses were performed with GraphPad PRISM and unpaired Student's $t$-test, ${ }^{* * * *} p<0.0001(n \geq 8$ from 3 independent experiments).

\subsection{Early Silencing of HDAC3 Modulates Adipocyte Pro-Inflammatory Profile}

Inflammation is another important molecular aspect determining the adipocyte phenotype. Recent evidence indicates that expression of some inflammatory genes in adipocytes may be critical to maintain normal adipose tissue function [10,34]. Thus, we finally analyzed the expression profile of genes involved in adipose tissue inflammation in our experimental settings. In particular, the expression of monocyte chemoattractant protein-1 (Mcp1), a chemokine promoting monocyte/macrophage migration and infiltration, significantly increased when HDAC3 silencing occurred in adipocyte precursors (Figure 8A), while its expression significantly halved in HDAC3-silenced mature adipocytes (Figure 8B). The expression of pro-inflammatory cytokine interleukin 6 (Il6) was higher in adipocytes silenced at day 0 of differentiation (Figure 8A) and, similarly, although to a lower extent, in adipocytes silenced at day 7 (Figure 8B). We also analyzed the expression of collagen type 6a1 (Col6a1), which is enriched in adipocyte extracellular matrix and contributes to obesity-related inflammation of adipose tissue [35]. Its expression augmented with HDAC3 early silencing (Figure 8A), while no differences were observed when silencing occurred in differentiated adipocytes (Figure 8B). A similar expression profile was measured for inducible nitric oxide synthase (Nos2), important for cell signaling and involved in immune response initiation (Figure 8). Finally, we analyzed the expression of mesoderm-specific transcript (Mest), known as a regulator of adipocyte differentiation and size, but also involved in the adipocyte pro-inflammatory profile [36]. Mest expression significantly 
decreased with HDAC3 silencing at the beginning of differentiation (Figure 8A), while the decrease was milder with silencing at day 7 (Figure 8B).

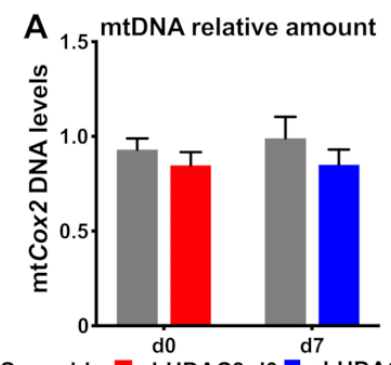

Scramble $\square$ shHDAC3 d0 $\square$ shHDAC3 d7
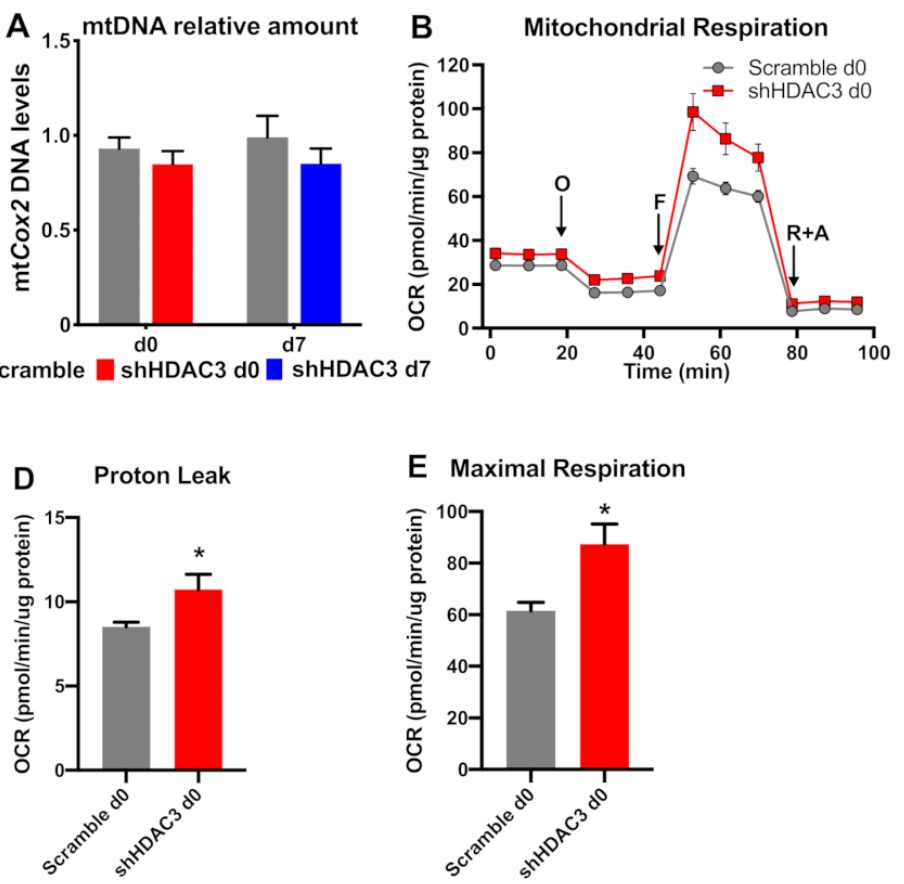

C Basal Respiration

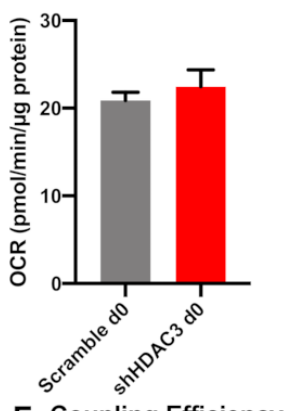

F Coupling Efficiency

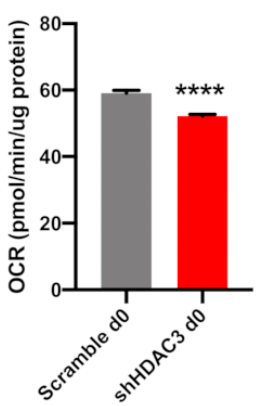

G

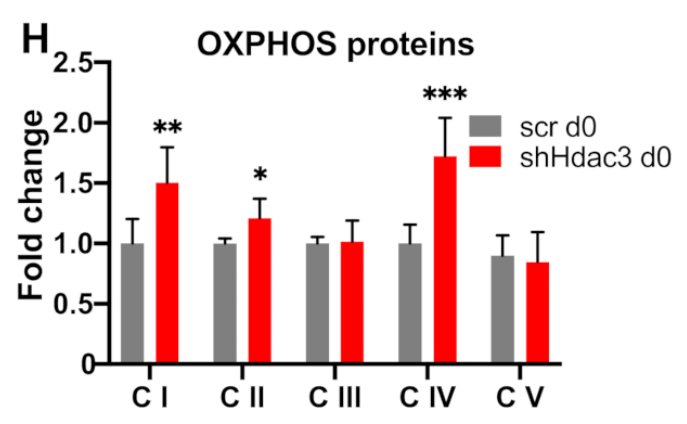

Figure 7. mtDNA levels and mitochondrial respiration in $\mathrm{C} 3 \mathrm{H} / 10 \mathrm{~T} 1 / 2$ adipocytes infected with scramble/shHDAC3. (A) Cells silenced at day 0 were harvested at day 9 after induction of differentiation, while cells silenced at day 7 were harvested at day 11 after induction of differentiation ( $n=18$ from 6 independent experiments). Cells silenced at day 0 were analyzed at day 9 after induction of differentiation for mitochondrial respiration (O, oligomycin addition; F, FCCP addition; rotenone + antimycin A addition) (B); basal respiration (C), proton leak (D), maximal respiration (E) and coupling efficiency (F) were calculated. Data are presented as mean \pm SEM. Statistical analyses were performed with GraphPad PRISM and unpaired Student's t-test, ${ }^{*} p<0.05$ and ${ }^{* * * *} p<0.0001(n=5)$. (G) Representative western blot of C3H/10T1/2 cells infected with scramble/shHDAC3 at d0 of differentiation to adipocytes to detect OXPHOS proteins: C I, complex I; C II, complex II; C III, complex III; C IV, complex IV; complex V (ATP synthase) was visible only at longer exposure of the film; however, the level of this complex did not differ between scramble and shHDAC3 (not shown). (H) Quantification of OXPHOS proteins from western blot in panel $(G)$; data are presented as mean \pm SEM; statistical analysis was performed with GraphPad PRISM using unpaired Student's $t$-test, ${ }^{*} p<0.05,{ }^{* *} p<0.01$ and ${ }^{* * *} p<0.001$ ( $n=6$ from 2 independent experiments). 

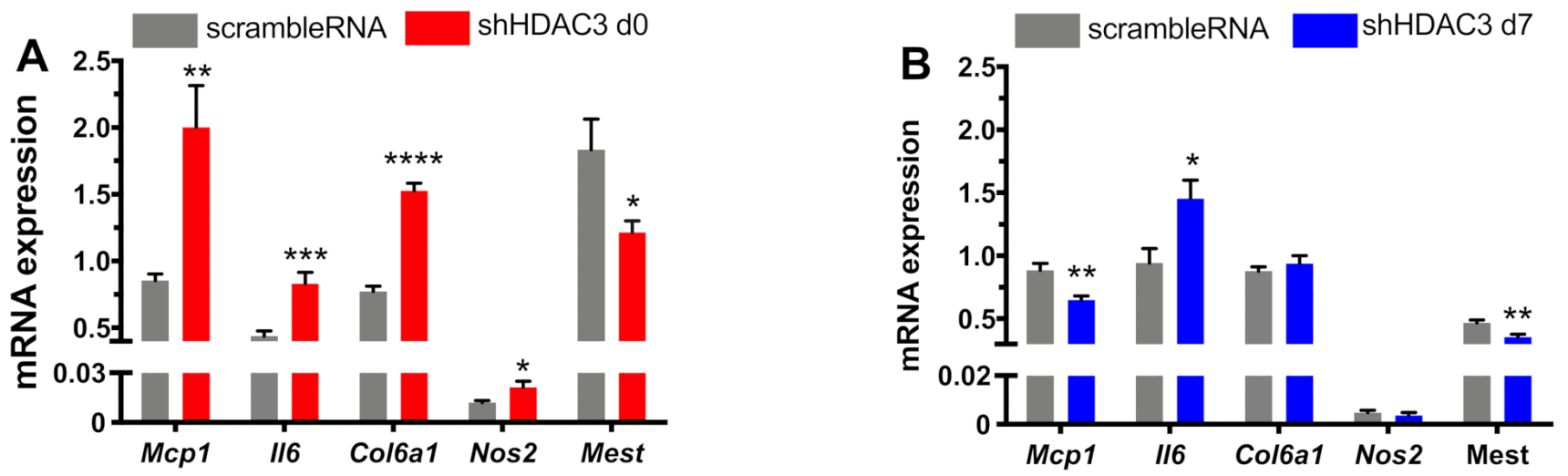

Figure 8. Expression of pro-inflammatory genes in $\mathrm{C} 3 \mathrm{H} / 10 \mathrm{~T} 1 / 2$ cells infected with scramble/shHDAC3 at day 0 (A) or at day 7 (B) of differentiation to adipocytes. Cells silenced at day 0 were harvested at day 9 after induction of differentiation, while cells silenced at day 7 were harvested at day 11 after induction of differentiation. Data are presented as mean \pm SEM. Statistical analyses were performed with GraphPad PRISM using unpaired Student's $t$-test, ${ }^{*} p<0.05,{ }^{* *} p<0.01,{ }^{* * *} p<0.001$, ${ }^{* * * *} p<0.0001$ ( $n=9$ from 3 independent experiments).

\subsection{HDAC3 Silencing in Precursor Cells Affects Gene Expression from Initial Stages of Adipocyte Differentiation}

To better characterize early events responsible for the effects of HDAC3 silencing, we performed a kinetic analysis of gene expression upon infection with shHDAC3 adenovirus. As shown in Figure 9, the expression of most of the abovementioned genes was significantly higher in HDAC3-silenced vs. scrambled shRNA adipocytes, as early as $72 \mathrm{~h}$ after induction of differentiation and silencing. Adipoq, Plin, Glut4 and Fabp 4 gene expression was amplified $72 \mathrm{~h}$ after HDAC3 silencing (Figure 9A). Notably, the expression of transcriptional regulators involved in adipogenesis, Cebpb, Srebf1c, Pparg and Cebpa was also higher in differentiating adipocytes $72 \mathrm{~h}$ after HDCA3 silencing, while the enhanced expression of carbohydrate-responsive element-binding protein $\beta$ (Chrebpb) was observed from day 5 (Figure 9B). This trend was defined for markers of browning, mitochondria functionality and metabolism such as Ucp1, Idh3a, Cox7a1, Atgl and Acadm. Furthermore, Adrb3 showed higher expression from $72 \mathrm{~h}$ and its increase became significant at day 9 (Figure 9C).

Collectively, our results indicate that HDAC3 plays a crucial role during early stages of adipocyte differentiation and seems to act as a rheostat of the adipocyte phenotype (i.e., white vs. beige adipocyte phenotype). 

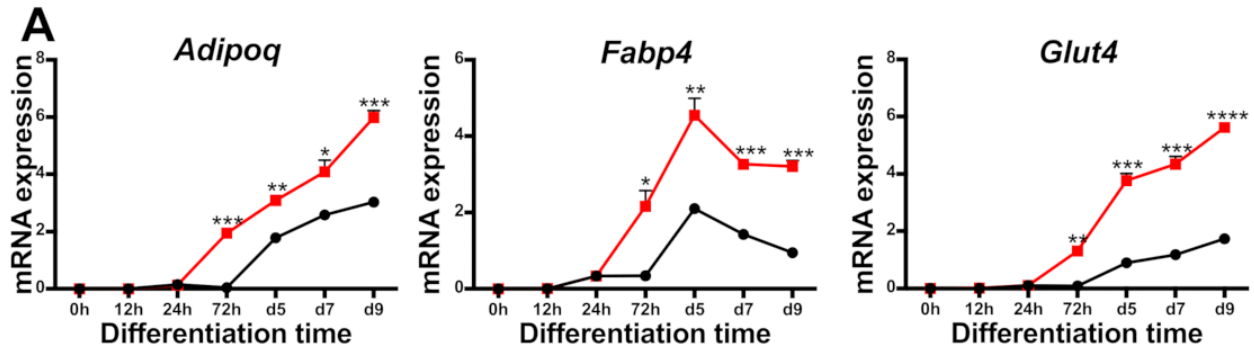

Plin
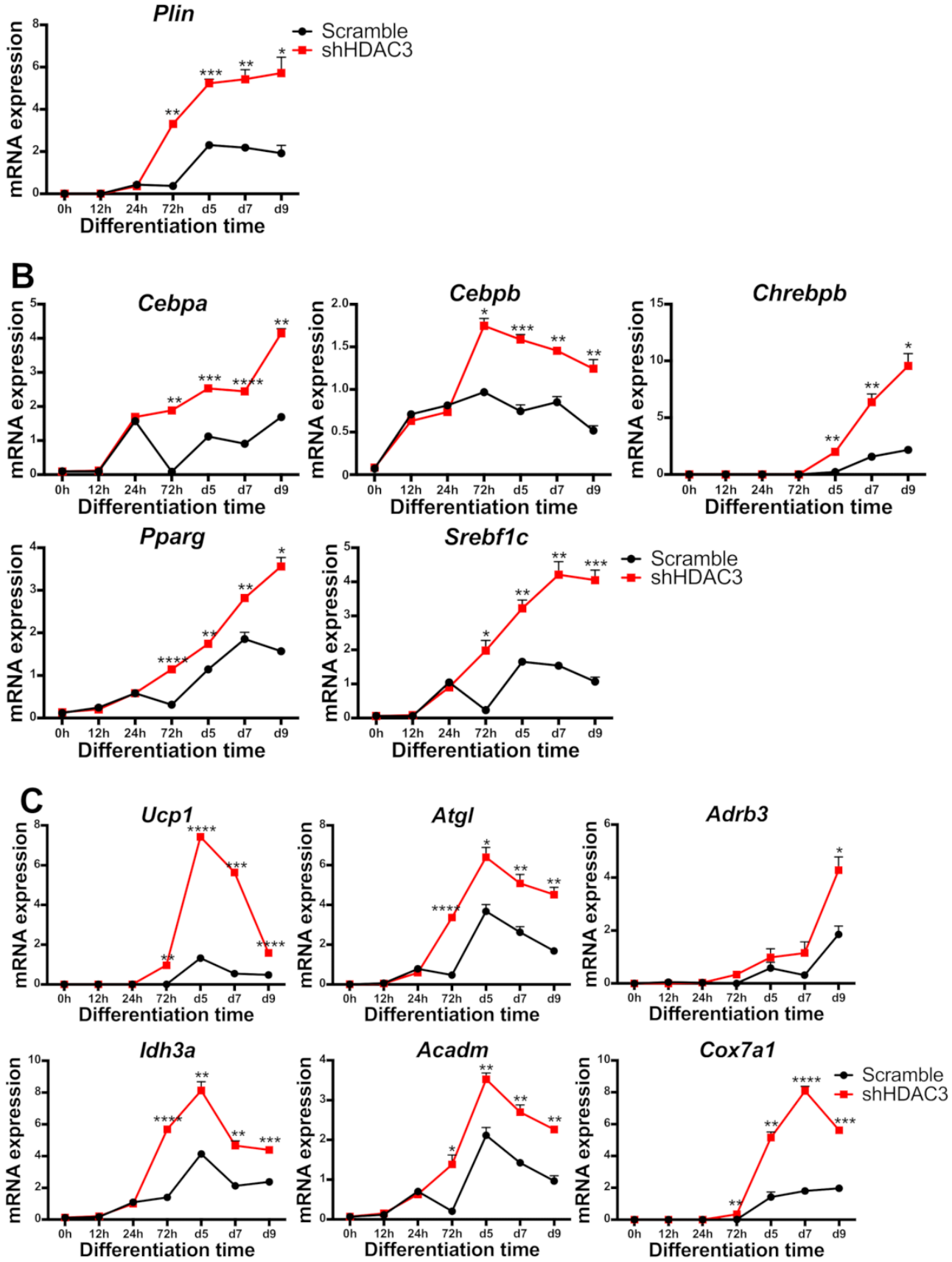

Figure 9. Kinetics of gene expression in $\mathrm{C} 3 \mathrm{H} / 10 \mathrm{~T} 1 / 2$ cells infected with scramble/shHDAC3 and induced to differentiate to adipocytes. Expression of genes involved in adipocyte functionality (A), differentiation (B) and browning and mitochondrial oxidative metabolism (C). Data are presented as mean \pm SEM of triplicate wells. Statistical analyses were performed using unpaired Student's $t$-test, ${ }^{*} p<0.05,{ }^{* *} p<0.01,{ }^{* * *} p<0.001,{ }^{* * * *} p<0.0001$. 


\section{Discussion}

We previously showed that pharmacological inhibition of class I histone deacetylases using MS-275 improves obese phenotype and insulin sensitivity in both $d b / d b$ [28] and diet-induced obese mice [29]. Furthermore, MS-275 amplifies the expression of genes important for adipocyte metabolism and browning in $\mathrm{C} 3 \mathrm{H} / 10 \mathrm{~T} 1 / 2 \mathrm{MSC}$ induced to differentiate to adipocytes [30]. Moreover, the metabolic effects of MS-275 were replicated in HDAC3-knockout mice in adipose tissue and in HDAC3-knockdown adipocytes [31].

Therefore, the aim of the present study was to understand whether the observed phenotypic effects were related to the actions of a specific class I HDAC in adipocyte precursors or in mature adipocytes. To this end, HDAC 3 was silenced in MSCs induced to differentiate to adipocytes (day 0 ) and in already differentiated adipocytes (day 7). The effects of HDAC 3 early silencing are consistent with the results obtained using the class I HDAC inhibitor MS-275. HDAC3 silencing at the beginning of differentiation promoted the expression of genes important for adipocyte functionality, browning and oxidative metabolism. Of note, in this study we showed that silencing of HDAC3 in $\mathrm{C} 3 \mathrm{H} / 10 \mathrm{~T} 1 / 2$ adipocytes rewired metabolism and led to the concomitant increase of the lipogenic and lipolytic pathways in a futile cycle of fatty acid metabolism required to support the metabolic demand of adipocyte browning. These data consistently reaffirm our previous results obtained with $\left[\mathrm{U}_{-}{ }^{13} \mathrm{C}_{16}\right]$-palmitate, showing stimulation of de novo fatty acid synthesis and $\beta$-oxidation in $\mathrm{C} 3 \mathrm{H} / 10 \mathrm{~T} 1 / 2$ adipocytes following HDAC3 silencing [31].

We also detected increased AKT phosphorylation, which suggests improved insulin signaling consequent to HDAC3 depletion in adipocytes. Interestingly, these results were accompanied by higher expression of the Chrebpb gene in adipose tissue, encoding a transcription factor that was previously shown to correlate with insulin sensitivity and possibly whole-body insulin action [33]. This transcription factor displays beneficial metabolic effects through the stimulation of glucose fate to de novo lipogenesis in adipocytes, thus integrating adipocyte and whole-body metabolism. Moreover, despite Ppargc1a expression decreasing in our model, the Ppargc1b isoform, whose expression was higher in HDAC3silenced adipocytes, is known to exert compensatory actions in controlling mitochondrial energy metabolism [37]. In this regard, it should be noted that Enguix et al. [38] reported Ppargc1b-mediated effects seem to have limited impact on mitochondrial biogenesis while it appears to be important to maintain the expression of genes for mitochondrial oxidative pathways. Altogether, our results suggest the adipocyte phenotype is related to increased functionality rather than a greater number of mitochondria. Accordingly, mtDNA content did not change in silenced adipocytes, while functional assays confirmed higher oxidative capacity and uncoupling of the electron transport chain (ETC) from ATP synthesis.

On the other hand, no significant differences are measured when silencing occurs later during the differentiation process. These data suggest that the reduction of HDAC 3 at early stages of differentiation, and possibly the related epigenome modifications, are crucial for cell commitment toward the brown-like phenotype, characterized by enhanced oxidative metabolism (Figure 10). Thus, the effects of class I HDAC inhibition or silencing might be exerted on adipocyte precursors rather than mature adipocytes. These conclusions are further corroborated by our kinetic analysis, which showed that expression of all the genes analyzed was increased starting from $24 \mathrm{~h}$ after induction of differentiation and silencing, suggesting HDAC3 impacts the adipocyte phenotype from the very first hours of differentiation. Based on our previous results, we predict that the molecular basis of HDAC3 early silencing might be similar to those demonstrated in CH3/10T1/2 adipocytes treated with MS-275 [30]. MS-275 was shown to increase H3K27 acetylation in Pparg and Ucp 1 enhancer regions as early as $12 \mathrm{~h}$ after the beginning of differentiation and consequently to upregulate the expression of these key genes by acting on early chromatin remodeling of their enhancer regions [30]. It is tempting to speculate that the early increased expression of transcription factors involved in adipogenesis, such as Pparg, Cebpa, Cebpb, Chrebpb and Srebf1, might be target of possible epigenetic effects related to 
HDAC3 silencing at the beginning of differentiation. More experiments will be necessary in the future to probe this hypothesis.

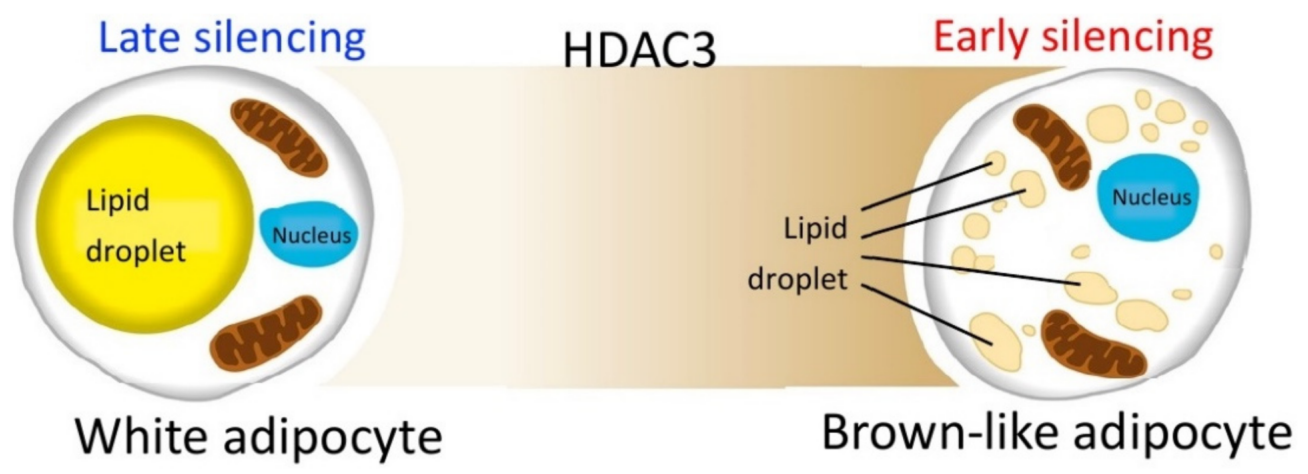

Figure 10. HDAC3 silencing during the early stages of differentiation is crucial for cell commitment toward the brown-like phenotype, characterized by enhanced oxidative metabolism.

Finally, the characterization of the role of HDAC3 on the adipocyte phenotype was extended to markers of inflammation, as we analyzed the expression of pro-inflammatory genes when HDAC 3 was silenced at the beginning or at the end of differentiation. The expression of Mcp1, Il6, Col6a1 and Nos2 significantly increased in HDAC3-early-silenced adipocytes, and this observation is consistent with previous reports showing that lowgrade inflammation in adipocytes is important for physiological adipose tissue expansion and remodeling and metabolic health [10,34]. In fact, expression of the analyzed genes increased only around 2-fold as compared to controls, while these markers usually greatly increase upon acute pro-inflammatory stimuli. In this regard, it is crucial to distinguish between inflammation originating in adipocytes and inflammation stemming from immune cells within adipose tissue. The former seems a key prerequisite for the proper function of adipocytes, assuring healthy adipose tissue expansion and remodeling. In addition, transient acute inflammation plays a beneficial role in healthy adipogenesis and metabolic homeostasis, while suppressed adipocyte inflammation has been shown to lead to systemic metabolic disturbances [10]. Therefore, adipose tissue inflammation could be an adaptive response that enables safe storage of excess nutrients. Furthermore, the suppression of adipocyte inflammation impairs adipose tissue function and promotes insulin resistance [34]. According to this view, inflammation in adipocytes could be considered as a protective adaptive response to potentially dangerous cues and it is critical to resolve tissue damage by initiating a repair process to reestablish tissue structure and function. Within this frame, we believe the increased expression of some inflammatory genes observed in HDAC3-silenced adipocytes, along with the metabolic rewiring and oxidative phenotype, could be viewed as a beneficial improvement of the adipocyte phenotype. The moderate upregulation of inflammatory marker genes may prelude to a later increase of the corresponding factors that may be detected only at later stages of inflammation onset. Thus, the increased expression of inflammatory genes could be regarded as an early marker of low-grade inflammation arising from adipocytes. Moreover, the expression of Mest, a factor involved in unhealthy adipose tissue expansion in an obesogenic environment [39], significantly decreased upon HDAC3 silencing, consistent with its role in the regulation of adipocyte differentiation and inflammation. On the other hand, the expression of proinflammatory genes did not increase with HDAC3 silencing at day 7, resulting in lower adipocyte differentiation and functionality as opposed to early silencing of HDAC3.

In conclusion, our results demonstrate HDAC 3 action during the very early stages of cell differentiation is essential to determine their phenotypic fate. Although the mechanistic basis of the effects of HDAC3 silencing needs to be investigated to delineate the key molecular events involved in the process, our results provide new evidence of the role played by a specific HDAC in determining the metabolic features of fully differentiated adipocytes. 


\section{Materials and Methods}

\subsection{Cell Culture and Differentiation}

$\mathrm{C} 3 \mathrm{H} / 10 \mathrm{~T} 1 / 2$, Clone 8 (ATCC ${ }^{\circledR}$ CCL-226 ${ }^{\mathrm{TM}}$, Manassas, VA, USA) were cultured in Dulbecco's Modified Eagle Medium (DMEM, Sigma-Aldrich, St. Louis, MO, USA) supplemented with $10 \%$ heat-inactivated fetal bovine serum (FBS, Euroclone, Pero, Italy), $1 \%$ L-glutamine (Life Technologies Italia, Monza, Italy) and 1\% penicillin-streptomycin (Life Technologies Italia, Monza, Italy). Differentiation was induced using growth medium with $5 \mu \mathrm{g} / \mathrm{mL}$ insulin (Sigma-Aldrich, St. Louis, MO, USA), $0.5 \mathrm{mM}$ 3-isobutyl-1-methylxanthine (Sigma-Aldrich, St. Louis, MO, USA), $2 \mu \mathrm{g} / \mathrm{mL}$ dexamethasone (Sigma-Aldrich, St. Louis, MO, USA) and $5 \mu \mathrm{M}$ rosiglitazone (Cayman Chemicals, Ann Arbor, MI, USA). For differentiation, cells were cultured in induction medium for 3 days and maintained in growth medium with $5 \mu \mathrm{g} / \mathrm{mL}$ insulin for 6 to 8 days (Figure 1) or as indicated in each figure legend. At the end of differentiation images of cells were captured with an Axiovert microscope (Carl Zeiss, Milano, Italia) at 10× magnification. Adipocytes were manually counted according to morphology and lipid accumulation.

\subsection{Cell Infection}

To silence Hdac3, 100 MOI shHDAC3 adenovector (Vector BioLabs, Malvern, PA, USA) was added to induction medium at day 0 or at day 7 to maintenance medium. Cells infected with 100 MOI Scramble were used as negative control (Figure 1). Infected cells were harvested at the end of differentiation. For kinetic experiments cells were harvested during differentiation, after $12 \mathrm{~h}, 24 \mathrm{~h}, 72 \mathrm{~h}, 5$ days, 7 days and 9 days from induction.

\subsection{Gene Expression}

Total RNA from cells cultured in 12-well plates was isolated using NucleoSpin RNA kit (Macherey-Nagel, Dueren, Germany) and quantified with Nanodrop (Life Technologies Italia, Monza, Italy). Real-time quantitative PCR was performed using iScriptTM One Step RT PCR for Probes (Bio-Rad Laboratories, Segrate, Italy), following the manufacturer's instructions. Primers and probes were obtained from Eurofins Genomics Italy (Vimodrone, Italy). The complete list is reported in Table 1. Specific mRNA amplification was normalized to 36B4 mRNA and quantified with the standard curve method. Data from three independent experiments were included for gene expression analyses.

Table 1. Sequences of primers and probes used for gene expression and mtDNA quantification analyses. Prdm16 and Adrb3 genes were analyzed using ABI mix (Life Technologies Italia, Monza, Italy).

\begin{tabular}{|c|c|c|}
\hline Gene & & $5^{\prime} \rightarrow 3^{\prime}$ Sequence \\
\hline \multirow{3}{*}{ Hdac3 } & Forward & TGTCTCAATGTGCCCTTACG \\
\hline & Reverse & CCTAATCGATCACAGCCCAG \\
\hline & Probe & ACTTCTACCAGCCGACGTGCATC \\
\hline \multirow{3}{*}{ Pparg } & Forward & TGTTATGGGTGAAACTCTGGG \\
\hline & Reverse & AGAGCTGATTCCGAAGTTGG \\
\hline & Probe & CCCTCGCTGATGCACTGCCTATGA \\
\hline \multirow{3}{*}{ Cebpa } & Forward & AGAGCCGAGATAAAGCCAAAC \\
\hline & Reverse & TCATTGTCACTGGTCAACTCC \\
\hline & Probe & AGCACCTTCTGTTGCGTCTCCA \\
\hline \multirow{3}{*}{ Cebpb } & Forward & CCCCGCGTTCATGCA \\
\hline & Reverse & CAGTCGGGCTCGTAGT \\
\hline & Probe & ACTTCCATGGGTCTAAAGGCG \\
\hline
\end{tabular}


Table 1. Cont.

\begin{tabular}{|c|c|c|}
\hline Gene & & $5^{\prime} \rightarrow 3^{\prime}$ Sequence \\
\hline \multirow{3}{*}{ Chrebpb } & Forward & CTGCAGATCGCGTGGAG \\
\hline & Reverse & GCAACTTGAGGCCTTTGAAG \\
\hline & Probe & CAAGCTGGTCTCTCCCAAGTGGAA \\
\hline \multirow{3}{*}{ Srebf1c } & Forward & ATGGATTGCACATTTGAAGACATGCT \\
\hline & Reverse & CCTGTGTCCCCTGTCTCAC \\
\hline & Probe & CTTCCCGGGCCTGTTTGACGCCCCCTA \\
\hline \multirow{3}{*}{ Adipoq } & Forward & AGGCATCCCAGGACATC \\
\hline & Reverse & ССТGTCATTCСААСАТСТСС \\
\hline & Probe & CCTTAGGACCAAGAAGACCTGCATCTC \\
\hline \multirow{3}{*}{ Plin } & Forward & ACAGACACAGAGGGAGAGG \\
\hline & Reverse & AGTGTTCTGCACGGTGTG \\
\hline & Probe & AGGAGGAAGAAGAGTCCGAGGCT \\
\hline \multirow{3}{*}{ Fabp4 } & Forward & GGCGTGGAATTCGATGAA \\
\hline & Reverse & GCTTGTCACCATCTCGTT \\
\hline & Probe & TGATGCTCTTCACCTTCCTGTCGT \\
\hline \multirow{3}{*}{ Glut4 } & Forward & TGTCGCTGGTTTCTCCAACTG \\
\hline & Reverse & CCATACGATCCGCAACATACTG \\
\hline & Probe & ACCTGTAACTTCATTGTCGGCATGGGTTT \\
\hline \multirow{3}{*}{ Ucp1 } & Forward & GAGCTGGTAACATATGACCTC \\
\hline & Reverse & GAGCTGACAGTAAATGGCA \\
\hline & Probe & ACAAAATACTGGCAGATGACGTCCC \\
\hline \multirow{3}{*}{ Ppara } & Forward & ACGCATGTGAAGGCTGTAAG \\
\hline & Reverse & CACTTGTGAAAACGGCAGTAC \\
\hline & Probe & CGGCTGAAGCTGGTGTACGACAA \\
\hline \multirow{3}{*}{ Cidea } & Forward & CACGCATTTCATGATCTTGG \\
\hline & Reverse & CCTGTATAGGTCGAAGGTGA \\
\hline & Probe & TTACTACCCGGTGTCCATTTCTGTCC \\
\hline \multirow{3}{*}{$L p l$} & Forward & GCCATGACAAGTCTCTGAAG \\
\hline & Reverse & СТTТСАAАСАСССАAАСAAGG \\
\hline & Probe & AGTCTGGCTGACACTGGACAAACA \\
\hline \multirow{3}{*}{ Atgl } & Forward & TCGTGTTTCAGACGGAGA \\
\hline & Reverse & CACATAGCGCACCCCT \\
\hline & Probe & TGCAGACATTGGCCTGGATGAG \\
\hline \multirow{3}{*}{$C d 36$} & Forward & GCGACATGATTAATGGCACAG \\
\hline & Reverse & GATCCGAACACAGCGTAGATAG \\
\hline & Probe & CAACAAAAGGTGGAAAGGAGGCTGC \\
\hline \multirow{3}{*}{ Cpt1b } & Forward & GATGCAGTTCCAGAGAATCC \\
\hline & Reverse & CTTGTTCTTGCCAGAGCT \\
\hline & Probe & TCTGСССАСТСТАСССТТССТС \\
\hline
\end{tabular}


Table 1. Cont.

\begin{tabular}{|c|c|c|}
\hline Gene & & $5^{\prime} \rightarrow 3^{\prime}$ Sequence \\
\hline \multirow{3}{*}{ Slc $25 a 20$} & Forward & TCTTTGGGTTTGGTCTGGG \\
\hline & Reverse & ATTTGATCCGTTCTCCAGGG \\
\hline & Probe & TCTCCAGAGGATGAACTTAGCTACCCAC \\
\hline \multirow{3}{*}{ Hadh } & Forward & TCTTGACTATGTTGGACTGGATAC \\
\hline & Reverse & AAGGACTGGGCTGAAATAAGG \\
\hline & Probe & CTTGGACGGGTGGCATGAAATGG \\
\hline \multirow{3}{*}{ Acadm } & Forward & ACCCAGATCCTAAAGTACCC \\
\hline & Reverse & CGAAAGCAATTCCTCTGGTG \\
\hline & Probe & TGGCCCATGTTTAGTTCCTTTTTTCCAA \\
\hline \multirow{3}{*}{ Acox 1} & Forward & TCACGTTTACCCCGGC \\
\hline & Reverse & CAAGTACGACACCATACCAC \\
\hline & Probe & CATCAAGAACCTGGCCGTCTGC \\
\hline \multirow{3}{*}{ Ppargc1b } & Forward & GGTGTTCGGTGAGATTGTAGAG \\
\hline & Reverse & GTGATAAAACCGTGCTTCTGG \\
\hline & Probe & TCTTTTACTTCTCGTCAGCACCTGGC \\
\hline \multirow{3}{*}{ Ppargc1a } & Forward & CATTTGATGCACTGACAGATGGA \\
\hline & Reverse & GTCAGGCATGGAGGAAGGAC \\
\hline & Probe & CCGTGACCACTGACA ACGAGGCC \\
\hline \multirow{3}{*}{$\operatorname{Idh} 3 a$} & Forward & ACGGAAGGAGAATACAGTGG \\
\hline & Reverse & GTACTCGAAGGCAAACTCTG \\
\hline & Probe & ACCСCATCAACGATCACATGCTCA \\
\hline \multirow{3}{*}{$m t \operatorname{Cox} 2$} & Forward & TGGTGAACTACGACTGCT \\
\hline & Reverse & CTGGGATGGCATCAGTTT \\
\hline & Probe & TGGCAGAACGACTCGGTTATCAACT \\
\hline \multirow{3}{*}{ Cox6a1 } & Forward & GTTCGTTGCCTACCCTCAC \\
\hline & Reverse & TCTCTTTAСТСАTСТTCATAGCCG \\
\hline & Probe & АССАТАСССТСТТССАСААСССТСА \\
\hline \multirow{3}{*}{ Cox7a1 } & Forward & TGTGGCAGAGAAGCAGAAG \\
\hline & Reverse & AGCCCAAGCAGTATAAGCAG \\
\hline & Probe & CGACAATGACCTCCCAGTACACTTGA \\
\hline \multirow{3}{*}{ Suclg1 } & Forward & AATGATCCAGCCACAGAAGG \\
\hline & Reverse & AGCAATGAAGGACACTACAGG \\
\hline & Probe & AGCATAACTCAGGTCCAAAGGCCAA \\
\hline \multirow{3}{*}{ Mcp1 } & Forward & CTCATGTACCCGCTGTATAG \\
\hline & Reverse & TTAGAGCCACGACCATACA \\
\hline & Probe & ATACTGGATGCCGTCTATGTCG \\
\hline \multirow{3}{*}{ Il6 } & Forward & ACGATAGTCAATTCCAGAAACC \\
\hline & Reverse & GTTGTCACCAGCATCAGT \\
\hline & Probe & CTTGCAGAGAGGAACTTCATAGC \\
\hline
\end{tabular}


Table 1. Cont.

\begin{tabular}{ccc}
\hline Gene & & $\mathbf{5}^{\prime} \rightarrow \mathbf{3}^{\prime} \mathbf{~}$ Sequence \\
\hline \multirow{3}{*}{ Col6a1 } & Forward & CTGGTGAAGGAGAACTATGCAG \\
\cline { 2 - 3 } & Reverse & GTCTAGCAGGATGGTGATGTC \\
\cline { 2 - 3 } Mest & Probe & CCGGGGAGGAGAATGTGATTGGA \\
\cline { 2 - 3 } & Forward & TTCTGTGTCCATCCCCATTC \\
\cline { 2 - 3 } & Reverse & CTGTGGGTAGTGGCTAATGTG \\
\hline \multirow{2}{*}{ Nos2 } & Probe & CGTACAGGAAAACGCTGCCGC \\
\cline { 2 - 3 } & Forward & CAACCCGAGCTCTTGTGTTGGA \\
\cline { 2 - 3 } & Reverse & CCATGGAGCATCCCAAGTACGAGT \\
\hline
\end{tabular}

\subsection{Lipid Content in Adipocytes}

Lipid content in $\mathrm{C} 3 \mathrm{H} / 10 \mathrm{~T} 1 / 2$ adipocytes was quantified using Oil Red O (ORO, Sigma-Aldrich, St. Louis, MO, USA) staining. ORO was extracted from stained samples in wells with $1.5 \mathrm{~mL}$ isopropanol via incubation for $10 \mathrm{~min}$, and absorbance was measured at $500 \mathrm{~nm}$.

\section{5. mtDNA Quantification}

DNA from cells cultured in 12-well plates was isolated using Nucleospin Tissue (Macherey-Nagel, Dueren, Germany) and quantified with Nanodrop (Life Technologies Italia, Monza, Italy). Real-time quantitative PCR was performed using an iScriptTM One-Step RT-PCR Kit for Probes (Bio-Rad Laboratories, Segrate, Italy) following the manufacturer's instructions and omitting iScript. Primers and probes of mtCox2 were obtained from Eurofins Genomics Italy (Vimodrone, Italy) (Table 1). A DNA quantity of mtCox2 was normalized to $36 \mathrm{~B} 4$ content. Data from three independent experiments were included for the analysis.

\subsection{Glycerol Release from Adipocytes}

Cell culture medium from $\mathrm{C} 3 \mathrm{H} / 10 \mathrm{~T} 1 / 2$ adipocytes grown and differentiated in 12-well plates was collected at the end of the experiment. Glycerol release in cell culture medium was measured with a Glycerol Assay Kit (Sigma-Aldrich, St. Louis, MO, USA) as an index of fatty acid $\beta$-oxidation.

\subsection{Measurement of Mitochondrial Respiration}

Mitochondrial respiration was assessed in mature adipocytes using Seahorse XFe24. A Cell Mito Stress Test (Agilent Technologies, Santa Clara, CA, USA) was performed following the manufacturer's instruction and serially injected with $1.5 \mu \mathrm{M}$ oligomycin, $1 \mu \mathrm{M}$ carbonyl cyanide-4-(trifluoromethoxy)phenylhydrazone (FCCP) and $0.5 \mu \mathrm{M}$ rotenone/antimycin A. Cells were seeded in Seahorse culture plates coated with gelatin $(0.1 \% w / v)$. After infection with scramble or shHDAC3 (Day 0), cells were differentiated until day 9. On the day of assay, the Seahorse assay medium was supplemented with $10 \mathrm{mM}$ glucose and $2 \mathrm{mM}$ glutamine ( $\mathrm{pH}$ 7.4). After assay performance, cells were lysed in RIPA buffer and proteins were quantified using BCA assay (Euroclone, Pero, Italy). Seahorse data were normalized to the total amount of proteins $(\mu \mathrm{g})$. Data were analyzed using Wave software, including the Seahorse XF Mito Stress Test Report Generator (Agilent Technologies, Santa Clara, CA, USA).

\subsection{Protein Analyses and Quantification}

Cells cultured in 6-well plates were lysed using Laemmli buffer. Lysates were homogenized with TissueLyser (Qiagen, Milano, Italy) and heated to $99^{\circ} \mathrm{C}$. Proteins were 
separated by SDS-PAGE and transferred to nitrocellulose membranes (GE Healthcare Life Sciences, Chicago, IL, USA). Sample loading and transfer was checked via Ponceau staining (Sigma-Aldrich, St. Louis, MO, USA). Membranes were blocked using $5 \%$ bovine serum albumin (Sigma-Aldrich, St. Louis, MO, USA) in TBS with 0.1\% Tween 20 (Sigma-Aldrich, St. Louis, MO, USA). Membranes were incubated with antibodies against HDAC3 (Santa Cruz Biotechnology, Dallas, TX, USA), phospho-AKT Ser473 and pan-AKT (Cell Signaling Technology, Danvers, MA, USA), antibody cocktail to detect mitochondrial proteins (Total OXPHOS Rodent WB Antibody Cocktail, Abcam, Cambridge, UK), PPAR $\gamma$ (Cell Signaling Technology, Danvers, MA, USA) or HSP90 antibody (Santa Cruz Biotechnology, Dallas, TX, USA) as a loading control. HRP-conjugated secondary antibodies were used for detection with chemiluminescence (Pierce ECL Western Blotting Substrate, Life Technologies Italia, Monza, Italy). Protein levels were quantified and normalized to HSP90 using ImageJ software (National Institutes of Health, Bethesda, MD, USA).

\subsection{Statistical Analyses}

Statistical analyses were performed using the unpaired two-tailed Student $t$-test with Prism (GraphPad, San Diego, CA, USA).

Author Contributions: Conceptualization, M.C. and D.C. (Dalma Cricrí); methodology, D.C. (Dalma Cricrí), L.C., S.P. and M.C.; formal analysis, D.C. (Dalma Cricrí) and L.C.; resources, M.C., N.M., E.D.F. and D.C. (Donatella Caruso); writing-original draft preparation, D.C. (Dalma Cricrí) and M.C.; writing-review and editing, D.C. (Dalma Cricrí), L.C., M.C., S.P., N.M., D.C. (Donatella Caruso) and E.D.F.; visualization, D.C. (Dalma Cricrí), L.C. and S.P.; supervision, E.D.F. and M.C.; project administration, M.C.; funding acquisition, M.C. and N.M. All authors have read and agreed to the published version of the manuscript.

Funding: This research was funded by a grant from the Ministry of Education, University and Research (MUR) Progetto Eccellenza (2018-2022), FP7 NR-NET PITN-GA-2013-606806 (MC), the CARIPLO Foundation 2015-0641 (MC) and the European Foundation for the Study of Diabetes (EFSD)/MSD European Research Programme on New Targets for Type 2 Diabetes 2019 (NM). The authors acknowledge support from the University of Milan through the APC initiative.

Institutional Review Board Statement: Not applicable.

Informed Consent Statement: Not applicable.

Data Availability Statement: The data presented in this study are available upon request from the corresponding author.

Acknowledgments: We thank Martina Crea for contribution to figures included in this manuscript. We are grateful to Marta Marchesi, Daniela Rossi and Elda Desiderio Pinto for administrative assistance.

Conflicts of Interest: The authors declare no conflict of interest.

$\begin{array}{ll}\text { Abbreviations } \\ \text { HDACs } & \text { Histone deacetylases } \\ \text { HDAC3 } & \text { Histone deacetylase 3 } \\ \text { MSCs } & \text { Mesenchymal stem cells } \\ \text { BMI } & \text { Body mass index } \\ \text { CREB } & \text { cAMP response element binding protein } \\ \text { C/EBP } & \text { CCAAT/enhancer-binding protein } \\ \text { SREBP-1c } & \text { Sterol regulatory element binding protein-1c } \\ \text { PPARG } & \text { Peroxisome proliferator-activated receptor gamma } \\ \text { WAT } & \text { White adipose tissue } \\ \text { BAT } & \text { Brown adipose tissue } \\ \text { UCP1 } & \text { Uncoupling protein 1 } \\ \text { ETC } & \text { Electron transport chain } \\ \text { FCCP } & \text { carbonyl cyanide-4-(trifluoromethoxy)phenylhydrazone } \\ \text { ChREBPB } & \text { Carbohydrate-responsive element-binding protein }\end{array}$




\begin{tabular}{|c|c|}
\hline PLIN & Perilipin \\
\hline FABP4 & Fatty acid binding protein 4 \\
\hline ADIPOQ & Adiponectin \\
\hline GLUT4 & Glucose transporter 4 \\
\hline CD36 & Cluster of differentiation 36 \\
\hline LPL & Lipoprotein lipase \\
\hline ATGL & Adipose triglyceride lipase \\
\hline СРT1B & Carnitine palmitoyl-transferase $1 \mathrm{~b}$ \\
\hline SLC25A20 & Solute carrier family 25 member 20 \\
\hline $\mathrm{HDAH}$ & Hydroxyacyl-coenzyme A dehydrogenase \\
\hline ACADM & Medium-chain acyl-CoA dehydrogenase \\
\hline ACOX1 & Peroxisomal acyl-coenzyme A oxidase 1 \\
\hline ADRB3 & $\beta 3$ adrenergic receptor \\
\hline PPARA & Peroxisome proliferator activator receptor $\alpha$ \\
\hline CIDEA & Cell death inducing DFFA-like effector $\alpha$ \\
\hline PRDM16 & PR domain containing 16 \\
\hline IDH3A & Isocitrate dehydrogenase subunit $\alpha$ \\
\hline $\operatorname{mtCOX} 2$ & Mitochondrial cytochrome c oxidase subunit 2 \\
\hline COX6A1 & Cytochrome c oxidase subunit $6 \mathrm{a} 1$ \\
\hline COX7A1 & Cytochrome c oxidase subunit 7a1 \\
\hline SUCLG1 & Succinyl-CoA ligase subunit 1 \\
\hline PPARGC1A & $\operatorname{PPAR} \gamma$ coactivator $1 \alpha$ \\
\hline PPARGC1B & $\operatorname{PPAR} \gamma$ coactivator $1 \beta$ \\
\hline MCP1 & Monocyte chemoattractant protein-1 \\
\hline IL6 & Interleukin 6 \\
\hline COL6A1 & Collagen type $6 a 1$ \\
\hline iNOS & Inducible nitric oxide synthase \\
\hline MEST & Mesoderm-specific transcript \\
\hline H3К27 & Lysine 27 Histone 3 \\
\hline
\end{tabular}

\section{References}

1. Caballero, B. Humans against Obesity: Who Will Win? Adv. Nutr. 2019, 10, S4-S9. [CrossRef]

2. WHO. Obesity and Overweight Key Facts. Available online: http://www.who.int/mediacentre/factsheets/fs311/en/ (accessed on 2 August 2021).

3. Cercato, C.; Fonseca, F.A. Cardiovascular risk and obesity. Diabetol. Metab. Syndr. 2019, 11, 74. [CrossRef] [PubMed]

4. Guilherme, A.; Virbasius, J.V.; Puri, V.; Czech, M.P. Adipocyte dysfunctions linking obesity to insulin resistance and type 2 diabetes. Nat. Rev. Mol. Cell Biol. 2008, 9, 367-377. [CrossRef]

5. Anandacoomarasamy, A.; Caterson, I.; Sambrook, P.; Fransen, M.; March, L. The impact of obesity on the musculoskeletal system. Int. J. Obes. 2008, 32, 211-222. [CrossRef] [PubMed]

6. Park, J.; Morley, T.S.; Kim, M.; Clegg, D.J.; Scherer, P.E. Obesity and cancer-Mechanisms underlying tumour progression and recurrence. Nat. Rev. Endocrinol. 2014, 10, 455-465. [CrossRef] [PubMed]

7. Ansari, S.; Haboubi, H.; Haboubi, N. Adult obesity complications: Challenges and clinical impact. Adv. Endocrinal. Metab. 2020, 11, 1-14. [CrossRef] [PubMed]

8. Russo, L.; Lumeng, C.N. Properties and functions of adipose tissue macrophages in obesity. Immunology 2018, 155, 407-417. [CrossRef]

9. Zatterale, F.; Longo, M.; Naderi, J.; Raciti, G.A.; Desiderio, A.; Miele, C.; Beguinot, F. Chronic Adipose Tissue Inflammation Linking Obesity to Insulin Resistance and Type 2 Diabetes. Front. Physiol. 2020, 10, 1607. [CrossRef] [PubMed]

10. Wernstedt Asterholm, I.; Tao, C.; Morley, T.S.; Wang, Q.A.; Delgado-Lopez, F.; Wang, Z.V.; Scherer, P.E. Adipocyte Inflammation Is Essential for Healthy Adipose Tissue Expansion and Remodeling. Cell Metab. 2014, 20, 103-118. [CrossRef] [PubMed]

11. Wang, Q.A.; Tao, C.; Gupta, R.K.; Scherer, P.E. Tracking adipogenesis during white adipose tissue development, expansion and regeneration. Nat. Med. 2013, 19, 1338-1344. [CrossRef]

12. Muller, S.; Ader, I.; Creff, J.; Leménager, H.; Achard, P.; Casteilla, L.; Sensebé, L.; Carrière, A.; Deschaseaux, F. Human adipose stromal-vascular fraction self-organizes to form vascularized adipose tissue in 3D cultures. Sci. Rep. 2019, 9, 7250. [CrossRef]

13. Arner, P.; Bernard, S.; Salehpour, M.; Possnert, G.; Liebl, J.; Steier, P. Dynamics of human adipose lipid turnover in health and metabolic disease. Nature 2011, 478, 110-113. [CrossRef]

14. Siersbæk, R.; Rabiee, A.; Nielsen, R.; Sidoli, S.; Traynor, S.; Loft, A.; Poulsen, L.L.C.; Rogowska-Wrzesinska, A.; Jensen, O.N.; Mandrup, S. Transcription factor cooperativity in early adipogenic hotspots and super-enhancers. Cell Rep. 2014, 7, $1443-1455$. [CrossRef] 
15. Siersbæk, R.; Mandrup, S. Transcriptional networks controlling adipocyte differentiation. Cold Spring Harb. Symp. Quant. Biol. 2011, 76, 247-255. [CrossRef]

16. Lefterova, M.I.; Haakonsson, A.K.; Lazar, M.A.; Mandrup, S. PPAR $\gamma$ and the global map of adipogenesis and beyond. Trends Endocrinol. Metab. 2014, 25, 293-302. [CrossRef]

17. Giralt, M.; Villarroya, F. White, brown, beige/brite: Different adipose cells for different functions? Endocrinology 2013, 154, 2992-3000. [CrossRef]

18. Sidossis, L.; Kajimura, S. Brown and beige fat in humans: Thermogenic adipocytes that control energy and glucose homeostasis. J. Clin. Investig. 2015, 125, 478-486. [CrossRef]

19. Kuryłowicz, A.; Puzianowska-Kuźnicka, M. Induction of adipose tissue browning as a strategy to combat obesity. Int. J. Mol. Sci. 2020, 21, 6241. [CrossRef]

20. Trayhurn, P.; Beattie, J.H. Physiological role of adipose tissue: White adipose tissue as an endocrine and secretory organ. Proc. Nutr. Soc. 2001, 60, 329-339. [CrossRef]

21. Park, A. Distinction of white, beige and brown adipocytes derived from mesenchymal stem cells. World J. Stem Cells 2014, 6, 33. [CrossRef]

22. Inagaki, T.; Sakai, J.; Kajimura, S. Transcriptional and epigenetic control of brown and beige adipose cell fate and function. Nat. Rev. Mol. Cell Biol. 2016, 17, 480-495. [CrossRef] [PubMed]

23. Donohoe, D.R.; Bultman, S.J. Metaboloepigenetics: Interrelationships between energy metabolism and epigenetic control of gene expression. J. Cell Physiol. 2012, 227, 3169-3177. [CrossRef] [PubMed]

24. Martinez, J.A.; Milagro, F.I.; Claycombe, K.J.; Schalinske, K.L. Epigenetics in Adipose Tissue, Obesity, Weight Loss, and Diabetes. Adv. Nutr. 2014, 5, 71-81. [CrossRef] [PubMed]

25. Rohde, K.; Keller, M.; la Cour Poulsen, L.; Blüher, M.; Kovacs, P.; Böttcher, Y. Genetics and epigenetics in obesity. Metabolism 2019, 92, 37-50. [CrossRef]

26. Ling, C.; Rönn, T. Epigenetics in Human Obesity and Type 2 Diabetes. Cell Metab. 2019, 29, 1028-1044. [CrossRef]

27. Ferrari, A.; Fiorino, E.; Giudici, M.; Gilardi, F.; Galmozzi, A.; Mitro, N.; Cermenati, G.; Godio, C.; Caruso, D.; De Fabiani, E.; et al. Linking epigenetics to lipid metabolism: Focus on histone deacetylases. Mol. Membr. Biol. 2012, 29, 257-266. [CrossRef] [PubMed]

28. Galmozzi, A.; Mitro, N.; Ferrari, A.; Gers, E.; Gilardi, F.; Godio, C.; Cermenati, G.; Gualerzi, A.; Donetti, E.; Rotili, D.; et al. Inhibition of class I histone deacetylases unveils a mitochondrial signature and enhances oxidative metabolism in skeletal muscle and adipose tissue. Diabetes 2013, 62, 732-742. [CrossRef] [PubMed]

29. Ferrari, A.; Fiorino, E.; Longo, R.; Barilla, S.; Mitro, N.; Cermenati, G.; Giudici, M.; Caruso, D.; Mai, A.; Guerrini, U.; et al. Attenuation of diet-induced obesity and induction of white fat browning with a chemical inhibitor of histone deacetylases. Int. J. Obes. 2017, 41, 289-298. [CrossRef]

30. Ferrari, A.; Longo, R.; Peri, C.; Coppi, L.; Caruso, D.; Mai, A.; Mitro, N.; De Fabiani, E.; Crestani, M. Inhibition of class I HDACs imprints adipogenesis toward oxidative and brown-like phenotype. Biochim. Biophys. Acta (BBA)-Mol. Cell Biol. Lipids 2020, 1865, 158594. [CrossRef]

31. Ferrari, A.; Longo, R.; Fiorino, E.; Silva, R.; Mitro, N.; Cermenati, G.; Gilardi, F.; Desvergne, B.; Andolfo, A.; Magagnotti, C.; et al. HDAC3 is a molecular brake of the metabolic switch supporting white adipose tissue browning. Nat. Commun. $2017,8,93$. [CrossRef]

32. Nguyen, H.C.B.; Adlanmerini, M.; Hauck, A.K.; Lazar, M.A. Dichotomous engagement of HDAC3 activity governs inflammatory responses. Nature 2020, 584, 286-290. [CrossRef]

33. Herman, M.A.; Peroni, O.D.; Villoria, J.; Schön, M.R.; Abumrad, N.A.; Blüher, M.; Klein, S.; Kahn, B.B. A novel ChREBP isoform in adipose tissue regulates systemic glucose metabolism. Nature 2012, 484, 333-338. [CrossRef]

34. Zhu, Q.; An, Y.A.; Kim, M.; Zhang, Z.; Zhao, S.; Zhu, Y.; Asterholm, I.W.; Kusminski, C.M.; Scherer, P.E. Suppressing Adipocyte Inflammation Promotes Insulin Resistance in Mice. Mol. Metab. 2020, 39, 101010. [CrossRef]

35. Pasarica, M.; Gowronska-Kozak, B.; Burk, D.; Remedios, I.; Hymel, D.; Gimble, J.; Ravussin, E.; Bray, G.A.; Smith, S.R. Adipose tissue collagen VI in obesity. J. Clin. Endocrinol. Metab. 2009, 94, 5155-5162. [CrossRef] [PubMed]

36. Anunciado-Koza, R.P.; Manuel, J.; Mynatt, R.L.; Zhang, J.; Kozak, L.P.; Koza, R.A. Diet-induced adipose tissue expansion is mitigated in mice with a targeted inactivation of mesoderm specific transcript (Mest). PLoS ONE 2017, 12, e0179879. [CrossRef]

37. Uldry, M.; Yang, W.; St-Pierre, J.; Lin, J.; Seale, P.; Spiegelman, B.M. Complementary action of the PGC-1 coactivators in mitochondrial biogenesis and brown fat differentiation. Cell Metab. 2006, 3, 333-341. [CrossRef]

38. Enguix, N.; Pardo, R.; González, A.; López, V.M.; Simó, R.; Kralli, A.; Villena, J.A. Mice lacking PGC-1 $\beta$ in adipose tissues reveal a dissociation between mitochondrial dysfunction and insulin resistance. Mol. Metab. 2013, 2, 215-226. [CrossRef]

39. Nikonova, L.; Koza, R.A.; Mendoza, T.; Chao, P.-M.; Curley, J.P.; Kozak, L.P. Mesoderm-specific transcript is associated with fat mass expansion in response to a positive energy balance. FASEB J. 2008, 22, 3925-3937. [CrossRef] [PubMed] 